Jurnal Ekonomi, Bisnis dan Akuntansi (JEBA) Volume 22 No 4 Tahun 2020

\title{
ANALISIS REPAIR MAINTENANCE POLICY DAN PREVENTIVE MAINTENANCE POLICY UNTUK MEMINIMALKAN TOTAL MAINTENANCE COST PADA MESIN PLEATING PT DUTA NICHIRINDO PRATAMA
}

\author{
Nur Baeti Azizah ${ }^{{ }^{*}}$, Suci Indriati ${ }^{1}$, Retno Widuri ${ }^{1}$, Intan Shaferi ${ }^{1}$ \\ ${ }^{1)}$ Jurusan Manajemen, Fakultas Ekonomi dan Bisnis, Universitas Jenderal Soedirman, Indonesia \\ *Email Coresponding: bettymilzin@gmail.com
}

\begin{abstract}
ABSTRAK
Penelitian ini merupakan penelitian studi kasus pada mesin pleating dari PT Duta Nichirindo Pratama di Tangerang. Tujuan penelitian ini adalah untuk mengetahui biaya maintenance mesin pleating dengan menggunakan metode repair maintenance dan preventive maintenance, untuk mengetahui hasil perbandingan biaya total dengan menggunakan metode repair maintenance dan preventive maintenance. Hasil analisis repair maintenance policy dan preventive maintenance policy menunjukkan bahwa metode preventive maintenance dengan usulan jadwal yang tepat ternyata lebih efisien dibandingkan jika menggunakan metode repair maintenance. Berdasarkan hasil perhitungan menggunakan metode repair maintenance menunjukkan total maintenance cost sebesar Rp 8.312.205,- setiap terjadi kerusakan mesin, sedangkan hasil perhitungan menggunakan metode preventive maintenance menunjukkan total maintenance cost sebesar Rp 7.801.411,setiap periode 12 bulan sekali. Implikasi dari kesimpulan diatas yaitu dalam upaya meminimalkan biaya perawatan pada mesin maka perusahaan perlu melakukan perawatan mesin dengan menggunakan metode perawatan untuk memudahkan perusahaan dalam menentukan sebuah kebijakan perawatan mesin, sehingga perusahaan dapat menghasilkan produk yang berkualitas dan dapat menekan biaya perawatan serendah mungkin.
\end{abstract}

Kata Kunci : Maintenance, Repair Maintenance Policy, Preventive Maintenance Policy

\begin{abstract}
This research is a case study research on the pleating machine of PT Duta Nichirindo Pratama in Tangerang. The purpose of this research is to know the cost of maintenance of pleating machines by using repair maintenance policy and preventive maintenance policy, to know the results of total cost comparison by using repair maintenance policy and preventive maintenance policy. The analysis of repair maintenance policy and preventive maintenance policy showed that the maintenance preventive method with the correct schedule proved more efficient than if using repair maintenance method. Based on calculation result using repair maintenance method shows total maintenance cost of $R p$ 8,312,205,- each machine malfunction, while the calculation result using preventive maintenance method shows total maintenance cost of $R p$ 7,801,411,- every 1 months period. The implications of the above conclusion is in an effort to minimize the cost of maintenance on the machine then the company needs to do machine maintenance using treatment methods to facilitate the company in determining a policy of machine maintenance, so that the company can produce a quality product and can reduce maintenance costs as low as possible.
\end{abstract}

Keywords: Maintenance, Repair Maintenance Policy, Preventive Maintenance Policy 


\section{PENDAHULUAN}

Maintenance merupakan aktivitas perawatan atau pemeliharaan mesin dengan tujuan agar mesin tetap berada pada kondisi operasi yang baik. Aktivitas ini merupakan aktivitas yang sangat esensial dilakukan pada setiap perusahaan manufaktur, karena hal tersebut akan berdampak kepada kegiatan produksi secara langsung. Mesin pada sebuah pabrik manufaktur biasanya beroperasi selama 24 jam sehingga tingkat kemungkinan terjadinya kerusakan cukup rawan terjadi. Hal ini mengharuskan perusahaan untuk menetapkan tindakan perawatan seperti apa yang akan diterapkan, dengan tujuan menjaga performa mesin agar tetap dapat bekerja secara maksimal dan meminimalisir kerugian yang terjadi akibat terjadinya kerusakan.

Breakdown dapat didefinisikan sebagai berhentinya suatu mesin pada saat produksi. Atau dengan kata lain mesin mengalami kerusakan. Breakdown dapat terjadi jika mesin mengalami kerusakan yang akan mempengaruhi kemampuan mesin, mempengaruhi kualitas produk yang dihasilkan dan menyebabkan penurunan hasil proses produksi. Breakdown pada mesin disebabkan oleh beberapa faktor yaitu : umur mesin, kebocoran, debu, karat, cacat, retak, kualitas sparepart yang rendah, kurang perawatan pencegahan, dan faktor-faktor lainnya.

Tujuan dari preventive maintenance adalah mengurangi terjadinya breakdown pada mesin sehingga produk yang dihasilkan sesuai dengan rencana, baik mutu, biaya maupun ketepatan waktunya. Tujuan dari repair maintenance adalah memperbaiki terjadinya breakdown pada mesin sehingga dilakukan perawatan karena adanya hasil produk tidak sesuai dengan rencana, baik mutu, biaya, maupun ketepatan waktunya. Total maintenance cost (TMC) adalah total biaya masingmasing kebijakan perawatan yang dikeluarkan perusahaan untuk merawat mesin dan peralatan produksi dalam masa operasinya dengan menggunakan metode preventive maintenance maupun dengan repair maintenance.

PT Duta Nichirindo Pratama merupakan perusahaan manufaktur yang bergerak dalam bidang industri pembuatan suku cadang asli berupa filter kendaraan untuk berbagai jenis kendaraan motor dengan customer seperti Honda, Kawasaki dan Mitsubishi. Proses produksi filter udara di PT Duta 
Nichirindo Pratama dalam beberapa tahapan yaitu: (1) Pleating adalah tahap paling awal dalam proses produksi filter udara (2) Injeksi Molding disebut tahap pembentukan material termo plastik (3) Spotting adalah proses assy material hasil injeksi molding dengan material steel, (4) Packing merupakan proses pengemasan untuk menyiapkan barang menjadi siap untuk ditransportasikan, di distribusikan, dijual, dan dipakai, (5) Storage merupakan proses penyimpanan produk finish good ke warehouse finish good, yang bertujuan untuk menghindarkan produk dari kerusakan dan kehilangan sebelum produk dikirim ke customer.

Proses pleating adalah salah satu bagian penting dalam proses pembuatan filter udara, karena merupakan awal dalam pembuatan filter udara. Dalam proses produksi filter udara, PT Duta Nichirindo Pratama membutuhkan pasokan bahan baku yang banyak untuk diproses di bagian pleating. Jumlah mesin pleating pada PT Duta Nichirindo Pratama yang tersedia adalah 15 unit. Selama periode Maret 2019 hingga Februari 2020 jumlah breakdown mesin pleating pada PT Duta Nichirindo Pratama sebanyak 78 kali. PT Duta Nichirindo Pratama dalam proses pembuatan filter udara mengutamakan bahan baku dengan kualitas yang tinggi sehingga menghasilkan produk yang berkualitas. Karena mesin setiap hari terus beroperasi terkadang mengalami breakdown yang tak terduga, sehingga menganggu proses produksi. Untuk mengatasi hal tersebut perusahaan perlu melakukan perawatan pada mesin produksi, khususnya mesin pleating.

PT Duta Nichirindo Pratama telah menerapkan kebijakan sistem perawatan preventive dengan periode tiap 1 bulan dan jumlah total biaya komponen preventive maintenance sebesar Rp 6.226.500, pada kebijakan sistem perawatan repair dengan periode berkala dan jumlah total biaya komponen repair maintenance sebesar $\mathrm{Rp}$ 9.420.500. Karena perusahaan telah menerapkan kebijakan perawatan preventive dengan periode setiap 1 bulan sekali, maka perusahaan mengalami biaya perawatan yang tinggi. Masalah utama PT Duta Nichirindo Pratama adalah tingginya frekuensi breakdown mesin, sehingga menyebabkan tingginya biaya pemeliharaan preventive. Ketidakseimbangan kedua biaya tersebut menjadi penyebab tingginya total maintenance cost. Maka dari itu perlu dilakukan penjadwalan perawatan sehingga mampu meminimumkan total maintenance cost. Penulis akan membahas masalah perawatan mesin pleating yang ada pada PT Duta Nichirindo Pratama. Pembahasan dilakukan untuk menentukan sebuah kebijakan perawatan mesin pleating yang tepat, efektif dan ekonomis, berdasarkan pada pengalaman frekuensi terjadinya breakdown mesin untuk meminimalkan biaya perawatan.

\section{TINJAUAN PUSTAKA DAN PERUMUSAN MODEL Maintenance}


Maintenance biasa disebut perawatan atau pemeliharan adalah suatu kegiatan yang bertujuan untuk menjaga atau memperbaiki suatu barang atau fasilitas secara fisik yang dapat digunakan secara terus menerus agar tetap dalam kondisi prima (Kurniawan, 2013). Perawatan merupakan kegiatan pemeliharaan mesin dan peralatan agar kondisi tetap stabil dan siap pakai untuk dipergunakan secara efektif, efisien dan akuntabel. Dengan adanya Maintenance, maka pelaksanaan proses produksi dalam perusahaan yang bersangkutan dapat berjalan lancar dan mesin dapat dipergunakan dalam jangka panjang.

\section{Pemilihan Kebijakan Repair Maintenance atau Preventive Maintenance Policy}

Menurut Pujo Tomo \& Kartha (2007) dan Zulaikah \& Fajriah (2009), dalam memilih antara kebijakan atau metode repair maintenance dan preventive maintenance, dapat dilaksanakan dengan perhitungan menggunakan metode-metode yang telah ada dengan tujuan untuk mencari biaya total maintenance (Total Maintenance Cost) yang paling rendah.

\section{Metode Repair Maintenance}

Repair maintenance atau bisa juga disebut dengan corrective maintenance adalah aktivitas perawatan atau pemeliharaan dengan cara menunggu mesin rusak setelah itu baru diperbaiki (Nachnul dan imron, 2013). kegiatan metode ini meliputi aktivitas persiapan tenaga kerja, adanya perjalanan, adanya alat dan peralatan test dan lain-lain.

Tujuan dari aktivitas ini ialah perbaikan yaitu menunggu sampai kerusakan terjadi kemudian diperbaiki agar msin produksi atau alat produksi dapat digunakan kembali sehingga dalam proses produksi dapat berjalan lancar (Prima, 2010).

\section{Metode Preventive Maintenance}

Preventive maintenance adalah aktivitas perawatan yang dilakukan untuk mencegah timbulnya kerusakan yang tidak terduga (Sudradjat, 2011). Mesin-mesin atau peralatan yang menggunakan metode preventive maintenance akan terjamin kelancarannya dan dalam kondisi siap pakai untuk proses produksi. Dimungkinkan bahwa pembuatan jadwal perawatan akan tepat dan rencana produksi akan sesuai target. Praktik di lapangan, metode preventive dalam perusahaan dapat dilakukan yaitu (Tampubolon, 2004) : 1) Routine maintenance, kegiatan perawatan yang dilakukan secara rutin, contoh setiap hari mengadakan pelumasan, pengecekan oli, pengisian dan pengecekan bahan bakar, termasuk pemanasan mesin, 2) Periodic maintenance, kegiatan perawatan yang dilakukan dengan memakai lamanya jam kerja mesin, sehingga perlu dibuat jadwal kerja, misalnya setiap 100 jam kerja, 500 jam kerja dan seterusnya, yang bersifat berkala dan periodik. Aktivitas ini lebih berat dari aktivitas perawatan rutin. Misalnya, pembongkaran mesin, penggantian spare part, service.

Dalam penelitian ini ada beberapa penelitian yang dijadikan acuan oleh penulis diantaranya adalah: (1) Anita Mustika Sari dan Desynta Elina Pangestuti (2017) menyatakan bahwa kebijakan 
perawatan yang paling optimal ialah kebijakan preventive maintenance jika dibandingkan dengan kebijakan repair maintenance. (2) Dhana Antasari dan Ary Arvianto (2018) menyatakan bahwa kebijakan perawatan yang optimal adalah kebijakan preventive maintenance. (3) Pramita Endah Kurniasari (2019) menyatakan bahwa metode preventive maintenance lebih baik digunakan dibandingkan metode repair maintenance, serta penelitian lainnya yang menggunakan metode preventive maintenance dan repair maintenance tentu memakai kedua metode tersebut guna untuk menentukan dan menerapkan metode sistem perawatan. Preventive maintenance policy dapat dipilih untuk dilaksanakan jika saat inspeksi teridentifikasi adanya kemungkinan atau probabilitas kerusakan yang tinggi. Hasil ini diharapkan mampu membuka pandangan perusahaan untuk menentukan sebuah kebijakan maintenance mesin pleating dengan usulan jadwal yang tepat, efektif dan ekonomis sehingga dapat menghasilkan produk yang berkualitas dan dapat menekan biaya pemeliharaan serendah mungkin. 


\section{METODE PENELITIAN DAN TEKNIK ANALISIS DATA Jenis Penelitian}

Dalam penelitian ini penulis menggunakan studi kasus dengan metode Preventive maintenance policy dan Repair Maintenance Policy yang merupakan penerapan dari perawatan mesin dengan mengambil suatu masalah kemudian menganalisisnya. Penelitian ini dilaksanakan di PT Duta Nichirindo Pratama bertempat di Jalan Palem Manis III No. 66 RT. 004/RW.003, Gandasari, Kec. Jatiuwung, Kota Tangerang, Banten, Jawa Barat. Objek penelitian yang akan digunakan dalam penelitian ini adalah berfokus pada perawatan mesin Pleating di PT Duta Nichirindo Pratama yang merupakan perusahaan suku cadang dengan produk Filter Kendaraan.

\section{Sumber data}

Sumber data yang digunakan dalam penelitian ini ada dua sumber data, yang pertama ada sumber data primer, data yang diperoleh dari hasil observasi dan wawancara dengan tenaga kerja yang langsung terlibat dalam pelaksanaan pemeliharaan/perawatan mesin. Yang kedua dari data sekunder yaitu data yang diperoleh dari literature seperti buku-buku teori, dokumen yang berisi informasi yang bersumber dari instansi yang bersangkutan dengan penelitian. Data yang diperlukan dalam penelitian ini yaitu sejarah berdirinya PT Duta Nichirindo Pratama, daftar tingkat breakdown mesin pada PT Duta Nichirindo Pratama dan data biaya komponen yang diganti.

\section{METODE ANALISIS DATA}

1) Tahap pertama menentukan distribusi kerusakan selama kurun waktu selama satu tahun. Cara menghitung probabilitas breakdown adalah :

jumlah mesin breakdwon pada periode tertentu

$$
\mathrm{P}=\overline{\text { jumlah seluruh breakdown mesin }}
$$

2) Tahap kedua menentukan besarnya biaya perbaikan Repair dan Preventive Maintenance. a. Biaya perbaikan repair maintenance, seperti persamaan dibawah ini :

$$
\mathrm{Cr}=\frac{\text { total biaya komponen }}{\text { jumlah komponen yang diganti }}
$$

b. Biaya perbaikan preventive maintenance, seperti persamaan dibawah ini :

$$
\mathrm{Cm}=(\text { Biaya tenaga kerja } \mathrm{x} \text { Waktu kerja } \mathrm{x} \text { Jumlah tenaga kerja })+(\text { Biaya komponen })
$$

3) Tahap ketiga melakukan perhitungan biaya perawatan mesin dengan menggunakan repair maintenance policy. $T M C(\mathrm{r})=T C r+T C d$ Keterangan :

$\mathrm{TCr}$ : Expected cost of repair per bulan 
$B \quad$ : Jumlah rata-rata breakdown perbulan untuk $N$ alat per mesin

$\mathrm{Cr}$ : biaya perbaikan

$\mathrm{Tb}$ : rata-rata runtime per alat sebelum rusak

$N$ : jumlah alat atau mesin

TCd : 0

Langkah-langkahnya :

1) $T b=P i . T i$

2) $B=-$

$T b$

3) $\mathrm{TCr}=\mathrm{B} . \mathrm{Cr}$

4) $T M C=T C r+T C d$

4) Tahap keempat melakukan perhitungan biaya yang dikeluarkan jika perawatan dengan menggunakan preventive maintenance policy.

$T M C(\mathrm{n})=T C r(\mathrm{n})+T C m(\mathrm{n})$ Keterangan

:

$T M C$ (n) : biaya total perawatan per bulan

$\mathrm{TCr}$ (n) : biaya repair per bulan $\mathrm{TCm}$

(n) : biaya preventive per bulan

Langkah-langkahnya adalah sebagai berikut :

1) $B=N . p$

n2) $B \stackrel{B}{=}$

$n$

3) $\mathrm{TCr}=\mathrm{B} \cdot \mathrm{Cr}$

m 4) $\mathrm{TCm}=$

$n$

5) $\mathrm{TMC}=\mathrm{TCr}+\mathrm{TCm}$

5) Tahap kelima membandingkan hasil cost dari 2 metode perawatan, lalu menggunakan salah satu kebijakan perawatan dengan mengambil Total Maintenance Cost (TMC) terkecil. 


\section{HASIL DAN PEMBAHASAN}

1. Menentukan distribusi kerusakan. Adapun rincian data breakdown mesin pleating, seperti pada tabel berikut :

Tabel 5. Data Breakdown Mesin Pleating

\begin{tabular}{lcc}
\hline \multicolumn{1}{c}{ Periode } & $\begin{array}{c}\text { Jumlah } \\
\text { kerusakan }\end{array}$ & $\begin{array}{c}\text { Probabilitas } \\
\text { breakdown }\end{array}$ \\
\hline Maret 2019 & 5 & 0,064 \\
\hline April 2019 & 4 & 0,051 \\
\hline Mei 2019 & 8 & 0,103 \\
\hline Juni 2019 & 4 & 0,051 \\
\hline Juli 2019 & 8 & 0,103 \\
\hline Agustus 2019 & 4 & 0,051 \\
\hline September 2019 & 4 & 0,051 \\
\hline Oktober 2019 & 7 & 0,090 \\
\hline November 2019 & 11 & 0,141 \\
\hline Desember 2019 & 9 & 0,115 \\
\hline Januari 2020 & $\mathbf{1 2}$ & $\mathbf{0 , 1 5 4}$ \\
\hline Februari 2020 & $\mathbf{2}$ & $\mathbf{0 , 0 2 6}$ \\
\hline Jumlah & 78 & \\
\hline
\end{tabular}

Dari tabel diatas dapat dilihat bahwa probabilitas breakdown tertinggi pada bulan Januari 2020 yaitu sebesar 0,154 dan probabilitas terendah pada bulan Februari 2020 sebesar 0,026. Probabilitas breakdown tiap periode memiliki nilai yang berbeda-beda, dimana waktu kerusakan sulit diprediksi sehingga nilai probabilitas tersebut menunjukkan distribusi yang tidak beraturan. Dalam hal ini mesin pleating termasuk jenis yang cukup kompleks karena mengalami banyak kerusakan, sehingga distribusi frekuensi breakdown mesin pleating bulan Maret 2019 sampai dengan bulan Februari 2020 termasuk jenis kasus 2.

\section{Menghitung biaya perbaikan}

Perhitungan biaya perbaikan repair maintenance 
Biaya perbaikan repair maintenance $(\mathrm{Cr})$ diperoleh dari biaya tenaga kerja ditambah biaya komponen, seperti pada persamaan berikut ini :

$\mathrm{Cr}=($ Biaya tenaga kerja $\mathbf{x}$ Waktu kerja $\mathbf{x}$ Jumlah tenaga kerja $)+($ Biaya komponen $)$ Waktu kerja bagian maintenance di PT Duta Nichirindo Pratama terdiri dari 3 shift dalam 1 hari yaitu pagi, siang, dan malam. Dalam seminggu memiliki 5 hari kerja yaitu hari Senin sampai dengan hari Jumat dengan jam kerja dalam seminggu 40 jam atau jam kerja dalam 1 hari adalah 8 jam. Dimana biaya tenaga kerja dibayar bukan berdasarkan waktu kerja dan jumlah tenaga kerja sehingga diabaikan karena dibayarkan setiap bulan oleh PT Duta Nichirindo Pratama, maka biaya perbaikan adalah biaya komponen yang diganti, seperti pada tabel berikut:

Tabel 6. Data biaya komponen repair maintenance

\begin{tabular}{llll}
\hline No & Tindakan Komponen & $\begin{array}{l}\text { Jumlah } \\
\text { komponen }\end{array}$ & Harga \\
1 & Penggantian kabel & 5 & Rp 2.934.000,00 \\
\hline 2 & Ganti $V$-Belt & 5 & Rp $137.500,00$ \\
\hline 3 & Ganti plat & 1 & Rp 2.964.000,00 \\
4 & Penggantian plat rusak & 1 & Rp 3.085.000,00 \\
-5 & Penggantianskun ring & 5 & Rp $300.000,00$ \\
\hline & Jumtah & 17 & $R p 9.420 .500,00$
\end{tabular}

(Sumber: Data PT Duta Nichirindo Pratama bulan Desember 2019)

Maka perhitungan biaya perbaikan repair maintenance, adalah sebagai berikut :

total biaya komponen

$\mathbf{C r}=$

jumlah komponen yang diganti

Rp 9.420 .500

$\mathrm{Cr}=\quad=\operatorname{Rp} 554.147,00$.

17

Berdasarkan perhitungan biaya perbaikan repair maintenance, maka hasil biaya perbaikan repair maintenance sebesar Rp 554.147,00..

b. Perhitungan biaya perbaikan preventive maintenance

Biaya perbaikan preventive maintenance $(\mathrm{Cm})$ ialah biaya perawatan yang dikeluarkan PT

Duta Nichirindo Pratama yang dilakukan secara rutin pada mesin pleating, meliputi biaya 
tenaga kerja dan biaya perawatan. Biaya tenaga kerja dibayarkan setiap bulan oleh PT Duta Nichirindo Pratama, sehingga biaya tenaga kerja diabaikan. Sedangkan biaya perawatan meliputi biaya pelumasan dan komponen kecil lain, seperti pada tabel berikut:

Tabel 7. Data biaya komponen preventive maintenance

\begin{tabular}{|c|c|c|c|}
\hline No & Tindakan Komponen & Jumlah komponen & Harga \\
\hline 1 & Penggantian $V$-Belt & 5 & Rp $137.500,00$ \\
\hline 2 & Pemasangan temperature & 1 & Rp 3.020.000,00 \\
\hline 3 & Cek, ganti tubular heater & 15 & Rp 2.934.000,00 \\
\hline 4 & $\begin{array}{l}\text { Pelumasan pillow block, } \\
\text { ganti baut, sekrup. }\end{array}$ & 2 & $\mathrm{Rp} \quad 135.000,00$ \\
\hline & Jumlah & 23 & $\operatorname{Rp} 6.226 .500,00$ \\
\hline
\end{tabular}

(Sumber: Data PT Duta Nichirindo Pratama bulan Desember tahun 2019)

Biaya tenaga kerja dapat diabaikan $=0$, maka jumlah keseluruhan biaya komponen seperti pada tabel 7 sebesar Rp 6.226.500,00. Perhitungan biaya perbaikan preventive maintenance secara rutin yang dilakukan PT Duta Nichirindo Pratama, adalah sebagai berikut :

$\mathrm{Cm}=($ Biaya tenaga kerja $\mathrm{x}$ Waktu kerja $\mathrm{x}$ jumlah tenaga kerja $)+($ Biaya Komponen $) \mathrm{Cm}$ $=(0)+(\operatorname{Rp~6.226.500)~}=\operatorname{Rp~6.226.500,00~}$

Sehingga diperoleh hasil biaya perbaikan preventive maintenance $(\mathrm{Cm})$ untuk PT Duta Nichirindo Pratama sebesar Rp 6.226.500,00.

3. Menghitung biaya perawatan mesin dengan menggunakan Repair Maintenance Policy Biaya yang timbul dalam metode perawatan repair ini adalah biaya repair dan biaya downtime, persamaan matematisnya sebagai berikut: $\mathbf{T M C}(\boldsymbol{r})=\mathbf{T C} \boldsymbol{r} \mathbf{T C d}$

Penentuan biaya produksi untuk mesin pleating dengan jumlah mesin sebanyak 15 unit memerlukan proses yang panjang, sehingga dapat diasumsikan bahwa biaya downtime dapat diabaikan $(T C d=0)$. Untuk menentukan $T C r$, harus menghitung rata-rata run-time tiap mesin $(T b)$, kemudian menghitung rata-rata breakdown tiap periode $(B)$.

$$
\begin{aligned}
& B=\frac{N}{T b} \\
& T b=\sum_{t}^{n}=1 p_{i} T i
\end{aligned}
$$

Dari distribusi frekuensi breakdown, didapat : 
$T b=\sum^{12} t=1 p_{i} T i$

a. Rata-rata run time mesin dihitung sebagai berikut :

$$
\begin{aligned}
& \boldsymbol{T b}=\boldsymbol{p 1 . T 1}+\boldsymbol{p 2 . T 2 + p 3 . T 3 + p 4 . T 4 + p 5 . T 5 + \ldots . . + p 1 2 . T 1 2} \\
& \mathrm{Tb}=(0,064)(1)+(0,051)(2)+(0,103)(3)+(0,051)(4)+(0,103)(5)+(0,051)(6)+ \\
& (0,051)(7)+(0,090)(8)+(0,141)(9)+(0,115)(10)+(0,154)(11)+(0,026)(12) \mathrm{Tb}=1 \\
& \text { bulan. }
\end{aligned}
$$

b. Rata-rata jumlah breakdown per periode dihitung sebagai berikut :

$$
\begin{aligned}
\boldsymbol{B} & =\frac{\boldsymbol{N}}{\boldsymbol{T} \boldsymbol{b}} \\
& =\frac{15}{1}=15
\end{aligned}
$$

\begin{tabular}{|c|c|c|c|c|}
\hline No & Rata-rata & Run & $T C r /$ bulan & $T M c /$ bulan \\
\hline & Time & & & \\
\hline
\end{tabular}

c. Biaya repair yang diperlukan ialah :

$$
\begin{array}{rl}
\boldsymbol{T C} \boldsymbol{r} & \boldsymbol{B} \boldsymbol{x} \boldsymbol{C r} \\
& =15 \times \mathrm{Rp} 554.147=\mathrm{Rp} 8.312 .205 \text { per bulan } \\
\boldsymbol{T M C} & =\boldsymbol{T C} \boldsymbol{r}+\boldsymbol{T C} \boldsymbol{d} \\
& =\mathrm{Rp} 8.312 .205+0=\mathrm{Rp} 8.312 .205 \text { per bulan }
\end{array}
$$

Sehingga rincian data biaya repair maintenance policy, seperti pada tabel berikut :

Tabel 8. Biaya repair maintenance policy

\begin{tabular}{llll}
\hline 1 & 1 & 8.312 .205 & 8.312 .205
\end{tabular}

Berdasarkan tabel 8, maka hasil perhitungan yang dilakukan oleh peneliti-dengan menggunakan metode repair maintenance ialah rata-rata run time sebanyak 1 bulan, biaya yang diperlukan (TCr) sebesar Rp 8.312.205 per bulan, dan Total Maintenance Cost (TMC) Repair Maintenance Policy sebesar Rp 8.312.205 per bulan. Langkah selanjutnya, peneliti melakukan perhitungan dengan menggunakan metode preventive maintenance.

4. Menghitung biaya perawatan mesin dengan menggunakan Preventive Maintenance Policy Perhitungan biaya perawatan menggunakan preventive maintenance policy untuk kerusakan pada 1 bulan operasi $(n=1)$ adalah sebagai berikut :

a. Kumulatif jumlah breakdown dalam 1 bulan operasi 


$$
\begin{aligned}
B 1 & =\boldsymbol{N} \times \boldsymbol{p} 1 \\
& =(15)(0,064)=0,96
\end{aligned}
$$

b. Rata-rata jumlah breakdown per 1 bulan operasi

$$
\begin{aligned}
& \boldsymbol{B}=\frac{\boldsymbol{B n}}{\boldsymbol{n}} \\
& 1 \mathrm{~B}= \\
& \mathrm{B}=\frac{\mathrm{B}-96}{1}=0,96 \text { per bulan }
\end{aligned}
$$

c. Perkiraan biaya repair 1 bulan operasi

$$
\begin{aligned}
\boldsymbol{T C r} 1 & =\boldsymbol{B} \cdot \boldsymbol{C} \boldsymbol{r} \\
& =(0,96)(\operatorname{Rp} 554.147)
\end{aligned}
$$

$$
=\operatorname{Rp} 531.981,00 \text {. }
$$

d. Biaya preventive maintenance per 1 bulan operasi

\section{N.Cm \\ $T C m 1=$}

$\boldsymbol{H}$

$$
\begin{aligned}
& =\frac{(15)(R p 6.226 .500)}{1} \\
& =\operatorname{Rp~93.397.500,00~}
\end{aligned}
$$

e. Total biaya maintenance per 1 bulan operasi

$$
\begin{aligned}
& \boldsymbol{T M C 1}=\boldsymbol{T} \boldsymbol{C r}(\mathbf{1})+\boldsymbol{T C} \boldsymbol{C}(\mathbf{1})+\boldsymbol{T C d} \\
& =531.981+93.397 .500+0 \\
& =\mathrm{Rp} 93.929 .481,00 .
\end{aligned}
$$

Dengan cara yang sama, Maka akan diperoleh hasil evaluasi biaya perawatan pada tiap periode bulan yang berbeda seperti pada tabel berikut :

Tabel 9. Biaya preventive maintenance policy

\begin{tabular}{lllllll}
\hline Bulan & Probabilitas & Bn & B & TCr & TCm & TMC \\
\hline 1 & 0,064 & 0,96 & 0,96 & 531.981 & 93.397 .500 & 93.929 .481 \\
2 & 0,051 & 0,765 & 0,383 & 212.238 & 46.698 .750 & 46.910 .988 \\
3 & 0,103 & 1,545 & 0,515 & 285.385 & 31.132 .500 & 31.417 .085 \\
4 & 0,051 & 0,765 & 0,191 & 105.842 & 23.349 .375 & 23.445 .217
\end{tabular}




\begin{tabular}{lllllll}
\hline 5 & 0,103 & 1,545 & 0,309 & 171.231 & 18.679 .500 & 18.850 .731 \\
\hline 6 & 0,051 & 0,765 & 0,128 & 70.930 & 15.566 .250 & 15.637 .180 \\
\hline 7 & 0,051 & 0,765 & 0,109 & 60.402 & 13.342 .500 & 13.402 .902 \\
\hline 8 & 0,090 & 1,35 & 0,169 & 93.650 & 11.674 .687 & 11.768 .337 \\
\hline 9 & 0,141 & 2,115 & 0,235 & 130.224 & 10.377 .500 & 10.507 .724 \\
\hline 10 & 0,115 & 1,725 & 0,173 & 95.867 & 9.339 .750 & 9.435 .617 \\
\hline 11 & 0,154 & 2,31 & 0,21 & 116.370 & 8.490 .681 & 8.607 .051 \\
\hline $\mathbf{1 2}$ & $\mathbf{0 , 0 2}$ & $\mathbf{0 , 3 9}$ & $\mathbf{0 , 0 3}$ & $\mathbf{6} .28$ & $\mathbf{7 . 7 8 3 . 1 2}$ & $\mathbf{7 . 8 0 1 . 4 1 1}$ \\
\hline $\mathbf{6}$ & & $\mathbf{3}$ & & & & $\mathbf{5}$ \\
\hline
\end{tabular}

Hasil perhitungan preventive maintenance policy pada tabel 9, diperoleh biaya perawatan yang paling rendah diperoleh pada periode 12 bulan sekali, dengan biaya preventive maintenance policy sebesar Rp 7.801.411,00. Hasil biaya tersebut menggambarkan tindakan metode perawatan yang paling baik untuk mesin pleating PT Duta Nihirindo Pratama, sehingga mendapatkan biaya perawatan yang ekonomis, penjadwalan perawatan yang tepat, dan efektif.

5. Membandingkan hasil cost dari 2 metode perawatan, lalu menggunakan salah satu kebijakan perawatan dengan mengambil Total Maintenance Cost terkecil.

Dari hasil pengolahan data, dapat diketahui total maintenance cost masing-masing metode maintenance untuk mesin pleating, baik dengan menggunakan repair maintenance policy maupun preventive maintenance policy.

Tabel 10. Perbandingan biaya maintenance

No TMC repair maintenance policy TMC preventive maintenance policy

$1 \quad \mathrm{Rp} 8.312 .205 \quad \mathrm{Rp} 7.801 .411$

Dari tabel perbandingan biaya maintenance, diketahui total maintenance cost pada preventive maintenance policy lebih murah dibandingkan repair maintenance policy. Dengan demikian, kebijakan perawatan yang optimal untuk PT Duta Nichirindo Pratama adalah menerapkan preventive maintenance policy dengan biaya sebesar Rp 7.801.411,00 per 12 bulan.

Pembahasan 
Sebagai perusahaan yang bergerak dibidang industri pembuatan suku cadang asli kendaraan bermotor, PT Duta Nichirindo Pratama dituntut untuk bisa menghasilkan produk yang berkualitas dengan mengutamakan bahan baku dengan kualitas tinggi. Karena mesin terus beroperasi selama 24 jam, kemungkinan terjadinya kerusakan cukup rawan terjadi dan waktu kerusakan mesin sulit diprediksi sehingga mengganggu proses produksi. Untuk mengatasi hal tersebut perusahaan memerlukan sebuah perawatan pada mesin dan peralatan produksi.

Dalam upaya menerapkan sistem maintenance untuk menekan breakdown yang terjadi, perusahaan telah menerapkan sistem maintenance pada mesin pleating dengan biaya perawatan menggunakan repair maintenance policy sebesar $\mathrm{Rp}$ 9.420.500,- pada periode berkala, biaya perawatan menggunakan preventive maintenance policy sebesar 6.226 .500 ,- pada periode tiap 1 bulan dan perbandingan antara metode repair maintenance policy dan preventive maintenance policy pada mesin pleating diketahui total maintenance cost pada preventive maintenance policy lebih murah dibandingkan repair maintenance policy, namun jika menggunakan preventive maintenance policy dengan periode setiap 1 bulan sekali menyebabkan perusahaan mengalami biaya perawatan yang tinggi jika dibandingkan dengan menggunakan repair maintenance policy. Ketidakseimbangan kedua biaya tersebut menyebabkan tingginya total maintenance cost. Perusahaan perlu memperhatikan dan segera melakukan tindakan perawatan yang tepat yang dapat memperbaiki permasalahan tersebut, sehingga mampu meminimumkan total maintenance cost.

\section{KESIMPULAN}

\section{Simpulan}

Berdasarkan analisis yang dilakukan pada PT Duta Nichirindo Pratama mengenai perawatan mesin pleating, dapat diperoleh kesimpulkan sebagai berikut: 1) Biaya perawatan mesin pleating pada PT Duta Nichirindo Pratama dengan menggunakan repair maintenance policy sebesar Rp 8.312.205,- setiap terjadi kerusakan mesin pleating; 2) Biaya perawatan mesin pleating pada PT Duta Nichirindo Pratama dengan menggunakan preventive maintenance policy sebesar Rp Rp 7.801.411,- setiap 12 bulan sekali; 3) Perbandingan antara repair maintenance policy dan preventive maintenance policy mesin pleating PT Duta Nichirindo Pratama, diketahui total maintenance cost pada preventive maintenance policy lebih murah dibandingkan repair maintenance policy. Dengan demikian, kebijakan perawatan yang optimal pada mesin pleating adalah kebijakan preventive maintenance policy dengan total maintenance cost terkecil sebesar Rp 7.801.411 yang dilakukan pada periode waktu setiap 12 bulan sekali. 


\section{Implikasi}

Implikasi Manajerial

Dari hasil penelitian diatas maka yang dapat dilakukan oleh manajer operasional pada PT Duta Nichirindo Pratama di antaranya: 1) menerapkan metode repair maintenance menggunakan periode berkala, 2) menerapkan metode preventive maintenance menggunakan periode waktu yang tepat karena dapat membantu mengoptimalkan perawatan mesin pleating, 3) mengambil metode maintenance untuk digunakan dengan membandingkan biaya terendah antara biaya metode repair maintenance dengan biaya metode preventive maintenance, 4) Melakukan pelatihan kepada pegawai yang bertugas untuk mengoperasikan mesin pleating, 5) Memelihara mesin agar mesin tidak cepat mengalami kerusakan Implikasi Teoritis Penelitian selanjutnya diharapkan dapat menerapkan metode repair dan preventive maintenance dengan periode yang sudah ditentukan, agar dapat memperpanjang usia kegunaan mesin. Penelitian selanjutnya diharapkan dapat Menjamin keandalan dan ketersediaan peralatan dan mesin secara teknis maupun ekonomis, sehingga dapat digunakan secara optimal

\section{DAFTAR PUSTAKA}

Ahyari, Agus. (2002). Manajemen Produksi - Pengendalian Produksi. Yogyakarta: BPFE.

Ansori, N. dan Mustajib, M.I. (2013). Sistem Perawatan Terpadu. Yogyakarta: Graha Ilmu.

Antasari, Dhana dan Arvianto. (2018). Analisis Repair Policy dan Preventive Maintenance Policy Untuk Mengetahui Biaya yang Optimal pada Mesin Pompa PT Pertamina TBBM Semarang Group. Jurnal Teknik Industri, Universitas Diponegoro.

Assauri, Sofyan. (2008). Manajmen Produksi dan Operasi. Jakarata: Universitas Indonesia.

Daulay, H. dan Delvika. (2017). Analisa Sistem Maintenance River Side Pump dengan Membandingkan Antara Breakdown dan Preventive Maintenance di Pabrik Gula Kwala Madu. Jurnal Teknik Industri, Universitas Medan Area Indonesia.

Eliska, Terrin, Endang Budiasih dan Judi Alhilman. (2017). Optimasi Kebijakan Maintenance dan Pengelolaan Spare Part Pada Mesin Caulking Line 6 dengan Menggunakan Metode Reliability Centered Maintenance (RCM) dan Reliability Centered Spares (RCS) Studi Kasus Pada PT DNS. Jurnal Teknik Industri Vol. 4, No. 2.

Haririn, Siti dan Wulandari. (2019). Perencanaan Perawatan Sebagai Pengoptimalan Biaya Downtime pada Mesin Flying Shear Menggunakan Metode Age Replacement di PT Hanil Jaya Steel. Jurnal Teknik Mesin, Universitas Negeri Surabaya.

Harsanto, Budi. (2013). Dasar Ilmu Manajemen Operasi. Bandung: UNPAD.

Heizer, Jay dan Render, Barry. (2011). Manajemen Operasi Buku Kedua. Jakarta: Salemba Empat.

Karunia, Rizky, Putro Ferro Ferdinant dan Evi Febianti. (2017). Usulan Penjadwalan Preventive Maintenance Pada Komponen Kritis Mesin Stone Crusher Menggunakan Model Age Replacement. Jurnal Teknik Industri Vol. 5, No. 3. 
Analisis Repair Maintenance Policy Dan Preventive Maintenance Policy Untuk Meminimalkan Total Maintenance Cost

Kurniasari, Pramita. (2019). Analisis Kebijakan Repair dan Preventive Maintenance pada Mesin Labeller Line 5 di PT Coca Cola Amatil Indonesia Central Java. Jurnal Teknik Industri, Universitas Diponegoro.

Kurniawan, Fajar. (2013). Teknik dan Aplikasi Manajemen Perawatan Industri, ed.1. Yogyakarta: Graha Ilmu.

Manzini, R. (2010). Maintenance for Industrial Systems. London: Springer.

Mustikasari, A. dan Pangestuti, D.E. (2017). Analisis Kebijakan Maintenance pada Transformator di PT PLN (Persero) Area Semarang. Jurnal Teknik Industri, Universitas Diponegoro Semarang.

Nurbani, Sofiani Nalwin dan Y.P. Jozzi Seftiadi. (2019). Analisis Perbandingan Metode Preventive Maintenance dan Corrective Maintenance Mesin Tenun pada Departemen Weaving di PT Bandung Sakura Textile Mills. Jurnal Teknik Industri Vol. 1, No. 1.

Pujotomo, D. Kartha, R. (2007). Analisa Sistem Perawatan Komponen Bearing Bottom Roller dan V-Belt Mesin Ring Frame RY-5 Pada Departemen Spinning II A (Di PT Danrilis Surakarta). Jurnal Teknik Industri Undip. Vol. 2 (2), pp. 40-48.

Rohmat, Yusup, Rachmatullah, Suliono dan Delffika Canra. (2017). Analisis Perancangan Jadwal Preventive dan Predictive Maintenance pada Mesin Kapal di Daerah Limbangan Indramayu. Jurnal Teknik Mesin, Politeknik Negeri Indramayu.

Sudrajat, A. (2011). Pedoman Praktis Manajemen Perawatan Mesin Industri. Bandung: PT Refika Aditama.

Susetyo, Ag Eko dan Nurhardianto. (2019). Penentuan Komponen Kritis Untuk Mengoptimalkan Keandalan Mesin Cetak. Jurnal Teknik Industri, Universitas Sarjanawiyata Tamansiswa Yogyakarta.

Tampubolon, P. Manahan. (2004). Manajemen Operasional. Jakarta: Ghalia Indonesia.

Zulaihah, L. Fajriah, N. (2009). Program Perencanaan Kebijakan Penjadwalan Preventive Maintenance Unit Mesin Las. Jurnal Bina Teknika. Vol. 5 (2), pp. 78-90.

Heizer, Jay dan Render, Barry. (2011). Manajemen Operasi Buku Kedua. Jakarta: Salemba Empat.

Karunia, Rizky, Putro Ferro Ferdinant dan Evi Febianti. (2017). Usulan Penjadwalan Preventive Maintenance Pada Komponen Kritis Mesin Stone Crusher Menggunakan Model Age Replacement. Jurnal Teknik Industri. Vol. 5, No. 3.

Kurniasari, Pramita. (2019). Analisis Kebijakan Repair dan Preventive Maintenance pada Mesin Labeller Line 5 di PT Coca Cola Amatil Indonesia Central Java. Jurnal Teknik Industri, Universitas Diponegoro.

Kurniawan, Fajar. (2013). Teknik dan Aplikasi Manajemen Perawatan Industri, ed.1. Yogyakarta: Graha Ilmu.

Manzini, R. (2010). Maintenance for Industrial Systems. London: Springer.

Mustikasari, A. dan Pangestuti, D.E. (2017). Analisis Kebijakan Maintenance pada Transformator di PT PLN (Persero) Area Semarang. Jurnal Teknik Industri, Universitas Diponegoro Semarang.

Nurbani, Sofiani Nalwin dan Y.P. Jozzi Seftiadi. (2019). Analisis Perbandingan Metode Preventive Maintenance dan Corrective Maintenance Mesin Tenun pada Departemen Weaving di PT Bandung Sakura Textile Mills. Jurnal Teknik Industri Vol. 1, No. 1.

Pujotomo, D. Kartha, R. (2007). Analisa Sistem Perawatan Komponen Bearing Bottom Roller dan V-Belt Mesin Ring Frame RY-5 Pada Departemen Spinning II A (Di PT Danrilis Surakarta). Jurnal Teknik Industri Undip. Vol. 2 (2), pp. 40-48. 
Jurnal Ekonomi, Bisnis dan Akuntansi (JEBA) Volume 22 No 4 Tahun 2020

Rohmat, Yusup, Rachmatullah, Suliono dan Delffika Canra. (2017). Analisis Perancangan Jadwal Preventive dan Predictive Maintenance pada Mesin Kapal di Daerah Limbangan Indramayu. Jurnal Teknik Mesin, Politeknik Negeri Indramayu.

Sudrajat, A. (2011). Pedoman Praktis Manajemen Perawatan Mesin Industri. Bandung: PT Refika Aditama.

Susetyo, Ag Eko dan Nurhardianto. (2019). Penentuan Komponen Kritis Untuk Mengoptimalkan Keandalan Mesin Cetak. Jurnal Teknik Industri, Universitas Sarjanawiyata Tamansiswa Yogyakarta.

Tampubolon, P. Manahan. (2004). Manajemen Operasional. Jakarta: Ghalia Indonesia.

Zulaihah, L. Fajriah, N. ( 2009). Program Perencanaan Kebijakan Penjadwalan Preventive Maintenance Unit Mesin Las. Jurnal Bina Teknika. Vol. 5 (2), pp. 78-90. 